Interdisciplinary Institute for Innovation

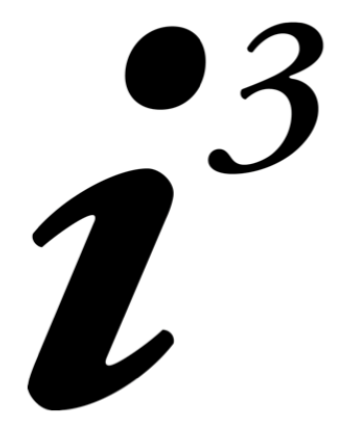

\title{
Optimal Recharging Strategy for Battery-Switch Stations for Electric Vehicles in France
}

Margaret Armstrong

Charles El Hajj Moussa

Jérôme Adnot

Alain Galli

Philippe Rivière

\section{Working Paper 12-ME-07}

November 2012

CERNA, MINES ParisTech

60 boulevard Saint Michel

75006 Paris, France 


\title{
Optimal Recharging Strategy for Battery-Switch Stations for Electric
}

\author{
Vehicles in France
}

\section{Armstrong ${ }^{1}$, C El Hajj Moussa ${ }^{2}$, J Adnot ${ }^{2}$, A Galli $^{1}$ \& P Riviere ${ }^{2}$}

1. Cerna, Mines-ParisTech, 60 Boulevard Saint-Michel, Paris France

2. Centre Energétique et Procédés, Mines-ParisTech, 60 Boulevard Saint-Michel, Paris France

Corresponding author: Margaret Armstrong

Date: 27 June 2012

\begin{abstract}
Most papers that study the recharging of electric vehicles focus on charging the batteries at home and at the work-place. The alternative is for owners to exchange the battery at a specially equipped battery switch station (BSS). This paper studies strategies for the BSS to buy and sell the electricity through the day-ahead market. We determine what the optimal strategies would have been for a large fleet of EVs in 2010 and 2011, for the V2G and the G2V cases. These give the amount that the BSS should offer to buy or sell each hour of the day. Given the size of the fleet, the quantities of electricity bought and sold will displace the market equilibrium. Using the aggregate offers to buy and the bids to sell on the day-ahead market, we compute what the new prices and volumes transacted would be. While buying electricity for the G2V case incurs a cost, it is possible to generate revenue in the V2G case, if the arrivals of the EVs are evenly spaced during the day. We compare the total cost of implementing the strategies proposed with the cost of buying the same quantity of electricity from EDF.
\end{abstract}

Keywords: day-ahead auction market, vehicle-to-grid, grid-to-vehicle 


\section{Introduction}

Over the next 10-15 years most European countries are planning to introduce electric vehicles $(E V)$ in order to reduce greenhouse gas emissions and to cut pollution levels in urban areas. According to Hacker et al (2009), the German government plans to have 1 million EVs by 2020 and 5 million by 2025 ; the Irish government aims for $10 \%$ of the national fleet to be electric by 2020 while the Spanish government has committed to having 1 million electric or hybrid cars on Spanish roads by 2014. The French grid operator has developed two scenarios for the introduction of EVs (RTE, 2009). In the reference scenario there will be 1 million EVS in 2020 and 2.7 million in 2025; the second scenario is more ambitious: it envisages 3.5 million EVs in 2020 and 6.7 million in 2025. In both cases the demand for electricity will increase considerably. The impact on the system will depend on when the batteries are recharged. Schneider et al (2011) studied three scenarios for recharging the batteries of one million EVs in the Washington-Baltimore Metropolitan Area:

- unmanaged charging,

- consumer-price incentivized recharging where price differentials in electricity tariffs are designed to dissuade car owners from recharging their batteries during peak periods,

- getting a central network operator (CNO) to coordinate the charging of a large number of batteries in response to real-time prices.

They concluded that the third option would lead to lower wholesale electricity prices as well as reducing load peaks. So in this paper we only consider the case where the charging of the batteries is coordinated.

Broadly speaking there are two ways of charging batteries: by plugging the EVs into a smart plug at the owner's home or workplace, or by exchanging the depleted battery for a fully charged one at a battery switch station (BSS). The impact of the first option has been studied by many authors including Rousselle (2009) for France, and Hadley and Tsvetkova (2009) and Lyon et al (2012) for the USA. In a study sponsored by the French grid operator RTE, Rousselle (2009) simulated the recharge times 
and the state of charge in the battery, in order to estimate the total load curve. Her analysis highlighted the impact of unmanaged charging on the load curves. She did not study the impact on electricity prices. Hadley \& Tsvetkova (2009) determined the marginal generation type in 12 regions in the USA, and hence the impact on wholesale prices for different recharging scenarios.

A recent study of the economic impact of smart meters by Lyon et al (2012) was motivated by a decision by the Colorado Public Utility Commission to disallow part of the costs of the "Smart Grid City" project in Boulder, Co, on the grounds that the benefits of the smart meters had not been adequately established. Using data from two different independent system operators, MISO in the Midwest and PJM on the east coast, they demonstrated that shifting charging from daytime to off-peak periods could lead to billions of dollars of savings. They concluded that while "time-of-use" pricing is worthwhile in both systems, the economic benefits of optimal charging of EVs did not appear to justify the costs of investing in the smart grid infrastructure required to implement real time pricing. To take advantage of the "time-of-use" pricing homeowners only need an appliance timer costing between $\$ 12$ and $\$ 60$ whereas they need a smart meter worth $\$ 150$ to respond to the real-time pricing.

As the option to recharge batteries at home or at the workplace has already been studied thoroughly, this paper focuses on the battery exchange option, and uses France to illustrate how the strategies could work. Initially we assumed that the BSS operator captured $10 \%$ of a fleet of 3 million EVs as its clients and that these 300,000 vehicles were recharged twice per week, giving 85,700 batteries to recharge per day on average. This corresponds to the usage pattern for the second family car in urban areas. But it rapidly became clear that the economics of the BSS depends on the number of batteries to be recharged per day and the number of spare batteries held by the BSS but not on the total number of EVs. For example, if 10,000 taxis sign up for a battery exchange contract, they would require an exchange battery at the end of each driver's shift (and possibly another while waiting for a fare at the airport). This alone would account for 20,000 to 30,000 batteries per day. 
The number of spare batteries held by the BSS has a marked influence on when the batteries are recharged. If the BSS has only a small number of batteries, it would be obliged to recharge them as soon as they arrive in order to have fully charge batteries available as clients arrive. As this would put a strain on the power supply at peak periods, we assume that the BSS has enough spare batteries to recharge them in off-peak periods.

Another important choice for the BSS operator is whether to provide power to the grid during peak hours (that is, operate in vehicle-to-grid mode, V2G) or just to buy power (that is, grid-to-vehicle G2V mode). The positive effects of vehicle-to-grid power transfers (V2G) are well-known: it lowers wholesale electricity prices and reduces the load at peak hours (Kempton and Tomic, 2005; Denholm and Short, 2006; Tomic and Kempton, 2007; Scott et al 2007). So we develop strategies for both the V2G and G2V operations.

In contrast to the PJM area which uses real-time locational marginal prices, few countries in Europe currently use nodal pricing, Poland being an exception (Sivorski, 2011), even though a recent study (Neuhoff et al, 2011) advocated it to reduce congestion. At present the day-ahead auction market is the main wholesale electricity market in western European countries. In some countries such as Ireland (Finn et al, 2012) and the Iberian Peninsula (Tomé Saraiva, 2007; Camus et al, 2011) there is a pool, but in Scandinavia and in the Central West Europe market (Benelux, France and Germany) only part of the electricity is sold through the organized market.

To buy/sell through the day-ahead auction market interested parties must send firm offers specifying prices and quantities for each 1-hour period (30 minutes in Ireland), before 11 am or 12 noon on the day prior to delivery. The electricity bourse compiles the aggregate curves of bids to buy electricity and of offers to sell for each hour and computes the intersection of the two curves to determine the market fixing price. This price applies to all buyers and sellers provided that the interconnection capacity is sufficient to allow the required transfers. Within France, the transmission and distribution grids are dense enough so that the same price applies throughout the country.

If a BSS were to set up business in France, the management could negotiate a contract to buy power directly from the historic utility, EDF, or one 
of its competitors. Alternatively the BSS could trade through the day-ahead market run by the bourse, Epexspot, but in order to trade, it would need a strategy for deciding how much to offer for each hour of the day ${ }^{1}$. This paper proposes strategies for buying and selling power through bourse, which have been optimized assuming that the management of the BSS aims to maximize corporate profits in the long-term by minimizing the operating costs of recharging the EVs in the short-term. Finally we compare the cost of using these strategies to recharge the batteries of the EVs with the cost of purchasing the same quantity of electricity at the price specified by the new NOME law²: $40 €$ in 2011 and $42 €$ per MWh in 2012.

This is not the first paper to propose algorithms for charging EVs. Taheri et al (2011) developed a demand response service for a fleet of around 10,000 PHEVs. They assume that vehicles plug in periodically over a given period of time (say 12 hours) and report their driving schedule for the next $n$ hours. To ensure that the total amount of electricity supplied to EVs stays within limits that are acceptable to utilities they put an hourly cap on charging. Earlier on, Han et al (2011) and Wu et al (2011) had constructed decision-making algorithms for minimum-cost recharging schedules which considered the vehicles individually rather than collectively as a fleet. Ma et al (2010) optimised the recharging to fill up the "overnight" valley. But none of these papers considered buying and selling via the day-ahead auction market.

The paper is structured is follows. The next section describes the methodology used and explains the assumptions that have been made. The results are presented in Section 3: firstly, the schedules for recharging the batteries; secondly, the cost of carrying out these schedules and thirdly their impact on the day-ahead market (i.e. on prices and on the volumes transacted). The conclusions follow in Section 4.

\footnotetext{
${ }^{1}$ We assume that the BSS operator is a price-taker who offers to buy/sell a certain quantity whatever the price. In the future we plan to work on optimising the price at which the BSS offers to buy/sell power.

${ }^{2}$ The French government recently passed the NOME law (short for Nouvelle Organisation des Marchés de l'Electricité) which requires the historic utility, EDF, to provide base-load electricity from nuclear power plants to new entrants at a regulated tariff ( $40 €$ in 2011 and $42 €$ per MWh in 2012). This price was designed to cover the full cost of nuclear energy including investments, production, decommissioning and the long-term storage of nuclear waste, as a benchmark for evaluating the cost of charging the batteries.
} 


\section{Research methodology}

The first step when optimising the schedules for recharging batteries is to decide what data to use. One possibility would be to use the data over a long period of time (e.g. several years). Three factors made us think that this is not appropriate. Firstly data from before the creation of the CWE market in November 2010 comes from a time when the market structure was different. Secondly, the markets are evolving gradually because of the introduction of renewable energy. The production mix is changing and so will the strategies of buyers and sellers on the bourse. Thirdly, electricity consumption is inherently seasonal, with marked differences between summer and winter, as well as between the different days of the week. For all these reasons we think that more robust strategies can be developed by using a relatively short training set that reflects the current market structure and trading practices.

We chose a moving training set consisting of the aggregated offers to buy/sell electricity on the day-ahead auction market during the previous 4 weeks. As the usage patterns vary from one day of the week to another, different strategies are developed for each day of the week and the training set consists of same day of the week over the previous four weeks. Public holidays are taken into account because electricity consumption is different on holidays compared to working days. Care is also required with the day in spring when Europe changes over from winter time to summer time and again in autumn with the change back to winter time ${ }^{3}$.

Market data for the past two years, 2010 and 2011, were used in the study. Over the past 5 years several important changes have been made to the structure of electricity markets in Western Europe. Firstly in 2007 the markets in France, Belgium and the Netherlands were coupled. This means that provided the transmission capacity was sufficient, the three countries had a common price. In November 2010 the Central Western European market was formed by coupling Germany with those three countries. So our study covers the period before and after a major structural change in the French electricity market. One of our objectives was to see how much the

\footnotetext{
${ }^{3}$ On the Saturday night in March of the change-over to day-light saving, there are only 23 hours, whereas in autumn there is a day with 25 hours.
} 
optimal strategies changed because of the market coupling with Germany, and whether there were problems just after the change-over when the training set uses data before the market coupling to determine the strategies applied afterwards.

The next point to decide was when the clients were likely to arrive and when the batteries would be charged. To simplify the computations we assumed that no clients arrive between 10pm and 6am. In G2V mode, the batteries are recharged from $10 \mathrm{pm}$ until $6 \mathrm{am}^{4}$ and all vehicles must be fully charged by $6 \mathrm{am}$ when clients start arriving. The G2V strategy gives the optimal amount to buy for each of these 8 hours. In V2G mode, all the batteries must also be fully charged by 6am but as the BSS can buy or sell at any time during the 24 hour period, the optimal strategy gives the amounts to buy or sell for each of the 24 hours. In contrast to the G2V case, the arrival times during the day have a marked effect on the V2G strategy. Two extreme scenarios are considered: (A) all EVs arrive at 6am and (B) the arrival of the EVs is spread evenly from 6am until 10pm.

It is assumed that on arrival batteries contain $10 \%$ of the nominal charge (24KWh). Secondly due to technical losses between the grid and the battery, $5 \%$ is lost each time a battery is charged or discharged (Badey, 2012 p13; Dang et al, 2010). By way of comparison, Lyon et al (2012) considered a battery capacity of $16 \mathrm{KWh}$ and a charging efficiency of $88 \%$ based on the specifications of the 2011 Chevy Volt. Like them we do not take account of the wear and tear on batteries due to charging and discharging.

The key step in the study is to determine the impact of buying or selling more power on the day-ahead market. Figure 1 shows a schematic representation of the offers to buy and the bids to sell electricity for a given hour ${ }^{5}$. As we have assumed that the BSS operator is a price-taker, an offer to buy power would shift the aggregate offers to buy to the right, leading to a higher price (Figure 2 left). Figure 2 (right) illustrates the effect of selling electricity, which drops the price.

\footnotetext{
${ }^{4}$ The times 10pm and 6am correspond to a cheap tariff proposed by EDF for heating hot water systems.

${ }^{5}$ In this figure the minimum price is 0 . This was the case before the market coupling with Germany. Since then the market has adopted the German convention of having a minimum
} 


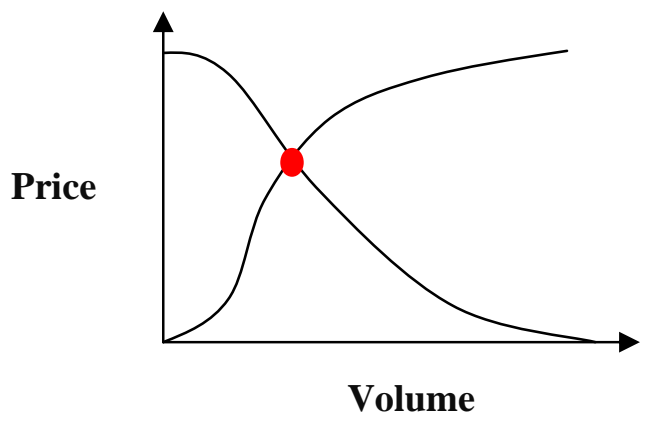

Figure 1: Aggregate offers to buy and sell electricity during a given hour. The intersection of the two curves gives the market fixing price and volume.

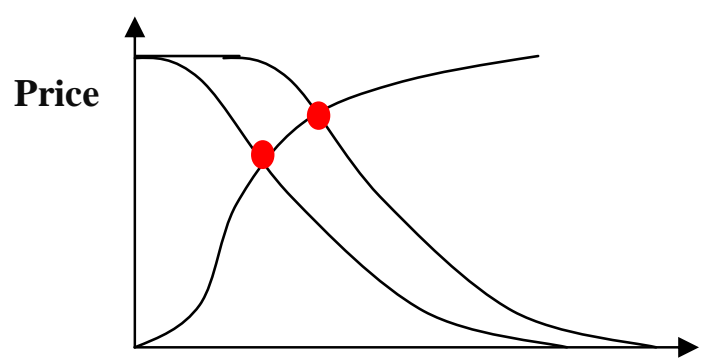

Volume

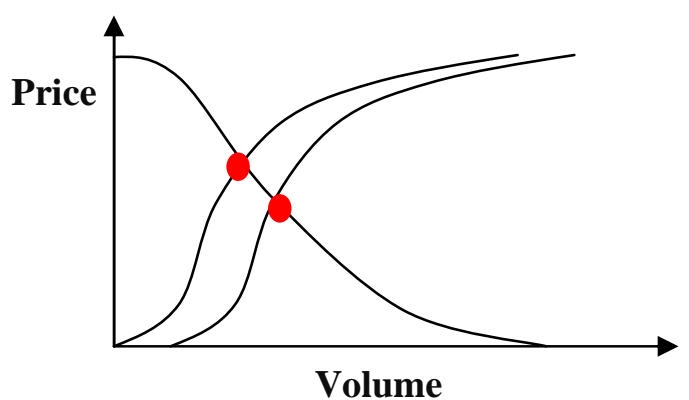

Volume

Figure 2: Aggregate offers. If the BSS wishes to buy power, the aggregate curve of offers to purchase would be shifted to right leading to a higher price (left); conversely if the BSS wishes to sell power, the aggregate curve of offers to sell would be shifted to right, leading to a lower price (right).

\section{Optimisation procedure}

Our objective is to determine the quantities $q_{i}$ of electricity to charge into or discharge from the batteries in the $\mathrm{i}^{\text {th }}$ hour for $\mathrm{i}=1, \ldots 24$, to ensure that all the batteries are fully charged by 6am the next day. By convention $\mathrm{q}_{i}$ is positive when the battery is being charged and negative when it is being discharged. The quantities to be bought or sold on the bourse depend on the extent of losses when charging and discharging the batteries. If the quantity $q_{i}$ is charged into the batteries after losing $5 \%$ of energy during the charging process, then the quantity bought on the bourse was $1.05 q_{\text {; }}$; and conversely if $q_{i}$ is discharged from the batteries, then $0.95 q_{i}$ will be available for sale on the bourse. 
Having chosen 6am is the reference time when all batteries must be fully charged, it is natural to number the hours as shown in Table 1. Hours numbered $\mathrm{i}=1$ through to 18 correspond to hours $\mathrm{H} 7$ to $\mathrm{H} 24$ on the bourse, while hours numbered $\mathrm{i}=19$ to 24 correspond to $\mathrm{H} 1$ to $\mathrm{H} 6$ the next day.

Table 1: Convention for numbering the 24 hours in the day, with $i=19, \ldots 24$ being on the next day

\begin{tabular}{|c|c|c|c|c|c|c|c|}
\hline $\mathrm{i}=$ & 1 & 2 & $\ldots$ & 18 & 19 & $\ldots$ & 24 \\
\hline Hour & $\mathrm{H} 7$ & $\mathrm{H} 8$ & $\ldots$ & $\mathrm{H} 24$ & $\mathrm{H} 1$ & & $\mathrm{H} 6$ \\
\hline
\end{tabular}

When the BSS sells electricity, the revenue generated is positive; conversely when it buys power, it incurs a cost. Let $p\left(q_{i}\right)$ be the contribution to the BSS's revenue from charging or discharging the quantity $q_{i}$ in the $i^{\text {th }}$ hour on a given day. Now we develop the equations for optimising the V2G case. Those for the G2V case are very similar except that $q_{1}=0, q_{2}=0 \ldots q_{18}=0$ and $q_{19}$ $\geq 0, q_{20} \geq 0 \quad \ldots \quad q_{24} \geq 0$. In both cases, the objective function ${ }^{6}$ has to be maximised subject to a certain number of constraints: $\phi=\sum_{i=1}^{24} q_{i} p\left(q_{i}\right)$.

Let $M$ be the number of spare batteries held by the BSS. Let $N_{\min }$ be the minimum number of batteries to be kept fully charged in case more clients than expected arrive on a given day. Let $A_{i}$ be the number of EVs expected to arrive in the $i^{\text {th }}$ hour that day. Clearly $M>\sum_{i=1}^{24} A_{i}+N_{\min }$. In our example, $M=100,000 ; N_{\min }=10,000$ and $\sum_{i=1}^{24} A_{i}=85700$. For simplicity we have assumed that the same number of batteries has to be charged each day of the week, but the methodology would be exactly the same if it varied.

Let $k$ be the capacity of each battery. On arrival batteries still have $10 \%$ residual charge. Since all $M$ batteries must be fully charged at 6am each

\footnotetext{
${ }^{6}$ To simplify the analysis the initial capital expenditure has been considered a sunk cost and has not been included in the objective function because it does not influence the optimisation of the day-to-day trading strategies. Similarly we ignore the revenue for tariffs paid by users.
} 
day, the first constraint concerns the net increase in the charge in the batteries:

$$
\sum_{\mathrm{i}=1}^{24} \mathrm{q}_{\mathrm{i}}=0.9 \mathrm{k} \times \sum_{\mathrm{i}=1}^{24} \mathrm{~A}_{\mathrm{i}}
$$

As the charge in the batteries cannot be less than zero or more than $100 \%$ of the capacity, there are also limits on the quantity that can be physically charged into the batteries or discharged from them in any given hour, and hence on the quantities that can be bought or sold. For the V2G case, these depend on the expected hourly arrivals $A_{i}$. During the first hour, $A_{1} E V s$ are expected to arrive. After those batteries have been exchanged and the quantity $q_{1}$ is charged into the batteries, the total charge left in the $M$ batteries in the BSS will be

$$
\mathrm{Mk}-0.9 \mathrm{~A}_{1} \mathrm{k}+\mathrm{q}_{1}
$$

This amount must be greater than $\mathrm{N}_{\min } \mathrm{k}$ and less than Mk:

$$
\begin{aligned}
& \mathrm{N}_{\text {min }} \mathrm{k} \leq \mathrm{Mk}-0.9 \mathrm{~A}_{1} \mathrm{k}+\mathrm{q}_{1} \\
& \Rightarrow 0 \leq\left(\mathrm{M}-\mathrm{N}_{\text {min }}-0.9 \mathrm{~A}_{1}\right) \mathrm{k}+\mathrm{q}_{1} \\
& \mathrm{Mk}-0.9 \mathrm{~A}_{1} \mathrm{k}+\mathrm{q}_{1} \leq \mathrm{Mk} \\
& \Rightarrow \mathrm{q}_{1} \leq 0.9 \mathrm{~A}_{1} \mathrm{k}
\end{aligned}
$$

By the $i^{\text {th }}$ hour in the day, a total of $\left(A_{1}+\ldots+A_{i}\right) E V s$ should have arrived. The cumulative amount put into the batteries and discharged from the batteries will be $\left(q_{1}+\ldots+q_{i}\right)$, so the total charge left in the batteries in the BSS will be

$$
M k-0.9 k \sum_{j=1}^{i} A_{j}+\sum_{j=1}^{i} q_{j}
$$

This gives the inequalities

$$
\begin{array}{ll}
0 \leq\left(\mathrm{M}-\mathrm{N}_{\min }-0.9 \sum_{\mathrm{j}=1}^{\mathrm{i}} \mathrm{A}_{\mathrm{i}}\right) \mathrm{k}+\sum_{\mathrm{j}=1}^{\mathrm{i}} \mathrm{q}_{\mathrm{j}} & \text { for } \mathrm{i}=1, \ldots 23 \\
\sum_{\mathrm{j}=1}^{\mathrm{i}} \mathrm{q}_{\mathrm{j}} \leq 0.9 \mathrm{k} \sum_{\mathrm{j}=1}^{\mathrm{i}} \mathrm{A}_{\mathrm{j}} & \text { for } \mathrm{i}=1, \ldots 23
\end{array}
$$

Because all the batteries must be fully charged by 6am, the constraint on the $24^{\text {th }}$ hour of the day is:

$$
\sum_{\mathrm{i}=1}^{24} \mathrm{q}_{\mathrm{i}}=0.9 \mathrm{k} \sum_{\mathrm{i}=1}^{24} \mathrm{~A}_{\mathrm{i}}
$$


Summing up, the system to be maximised is:

$$
\phi=\sum_{\mathrm{i}=1}^{24} \mathrm{q}_{\mathrm{i}} \mathrm{p}\left(\mathrm{q}_{\mathrm{i}}\right)
$$

Subject to the constraints

$$
\begin{array}{ll}
0 \leq\left(M-N_{\min }-0.9 \sum_{j=1}^{i} A_{i}\right) k+\sum_{j=1}^{i} q_{j} & \text { for } i=1, \ldots 23 \\
\sum_{j=1}^{i} q_{j} \leq 0.9 k \sum_{j=1}^{i} A_{j} & \text { for } i=1, \ldots 23 \\
\sum_{i=1}^{24} q_{i}=0.9 k \sum_{i=1}^{24} A_{i} & \text { for } i=24
\end{array}
$$

This system was solved using Matlab ${ }^{7}$ for every day of the year in 2010 and 2011 for the three cases: the G2V case, the V2G case for scenario $A$ when all the EVs arrive at $6 a m$ and the V2G case for scenario B when the arrivals of the EVs are evenly spread over the 16 hours from 6am until 10pm. The revenue generated by implementing this strategy (i.e. the optimal revenue that could be generated) was also computed. In addition we computed the new market fixing price and the new volume of transactions.

This procedure gives the strategy that would have been optimal ex post; that is, when all the other bids are known but it clearly cannot be implemented ex ante. The schedule that we propose to use is the average of the optimal strategies for the four days in the training set. We call this the realised schedule. The revenue that would actually be generated by applying this strategy in practice (i.e. using the actual aggregate curves for that day) is also computed. By definition this must be less than or equal to the optimal revenue. Finally we computed the average of the four optimal revenues corresponding to the four days in the training, to see whether it gave a good estimate of how much revenue the realised strategy would generate. We refer to it as the estimated revenue.

\footnotetext{
${ }^{7}$ The only difficulty was to find a quick way of evaluating the function $p(q)$ without having to compute the intersection of the updated aggregate curves to buy and to sell power. This is
} 


\section{Results}

The results will be presented in the following order: firstly the optimal and realised schedules for recharging the batteries; secondly, the values generated by carrying out these schedules and thirdly the impact that recharging the batteries would have on the day-ahead market (i.e. on prices and on the volumes transacted).

\section{Optimal and Realised Schedules}

The schedules give the quantity of electricity in MW to buy or sell each hour of the day on the day-ahead market. The optimal schedules were averaged over periods of 13 weeks in winter and summer 2010 (Figure 3) and in 2011 (Figure 4). Figures 5 and 6 present the corresponding averages of the realised schedules. In each case the solid black line is for the V2G case for scenario $A$ (when all EVs arrive at 6am), while the thick black dotted line is for the V2G case for scenario $B$ (when the arrivals of EVs are evenly spread from 6am until 10pm) and the solid red line is for the G2V case.

Both the optimal and the realised schedules vary from one day of the week to another but the main differences are between the weekend and the other five working days. To save space only two typical cases are presented: the schedules for 6am Sunday to 6am Monday, and for Gam Tuesday to 6am Wednesday. Looking at these figures we see that: 

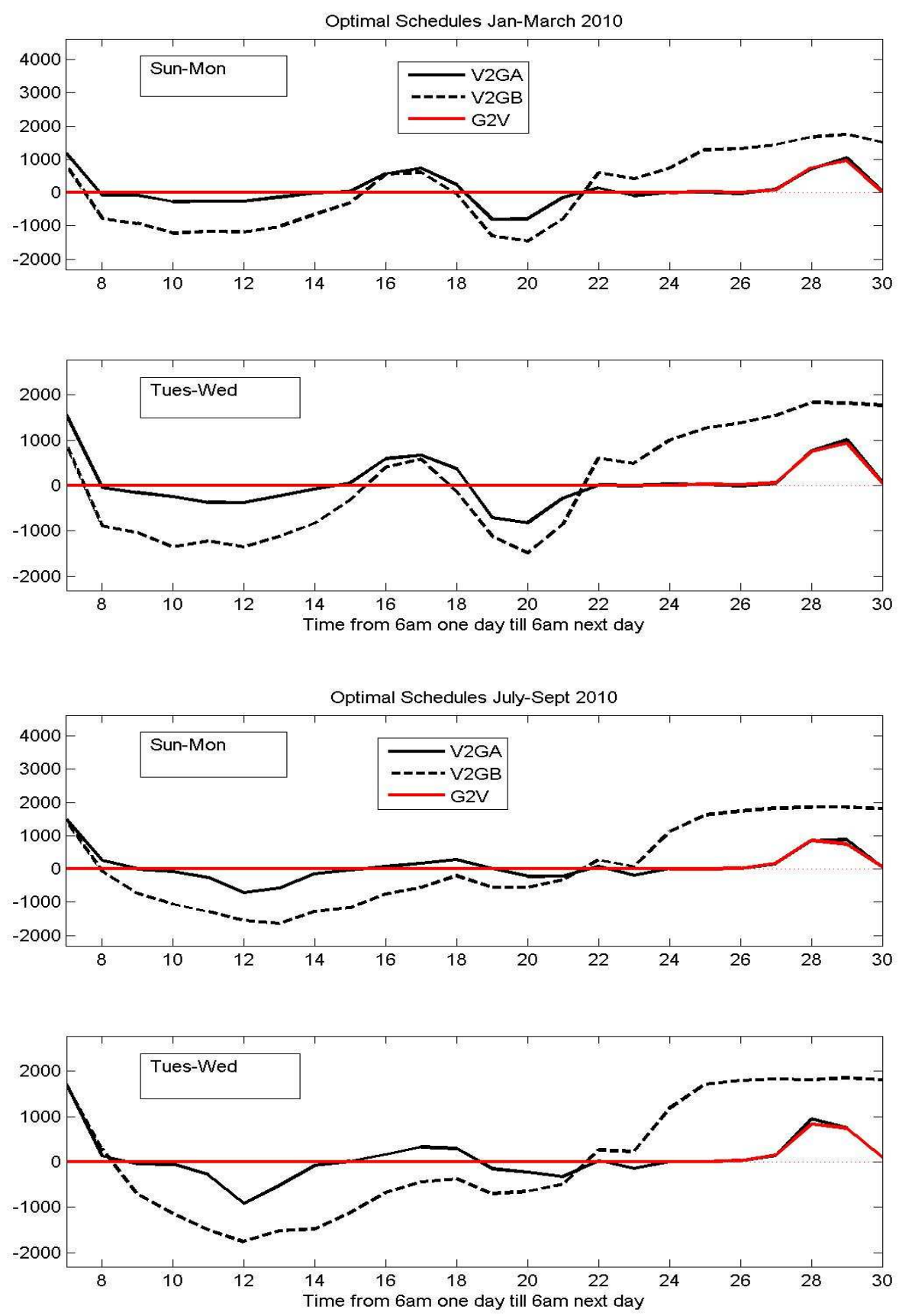

Figure 3: Average of the optimal schedules for the V2G case with scenario $A$ where all EVs arrive at 6am (solid black line), for the V2G case with scenario $B$ where the arrivals of EVs are evenly spread from 6am until 10pm (thick black dotted line) and for the G2V case (solid red line). In each case the averages (in MW) were computed over 13 weeks in 2010, in Jan-March (above) or July-Sept (below). The upper panel in each set of figures corresponds to Sun-Mon; the lower one, to Tues-Wed. 

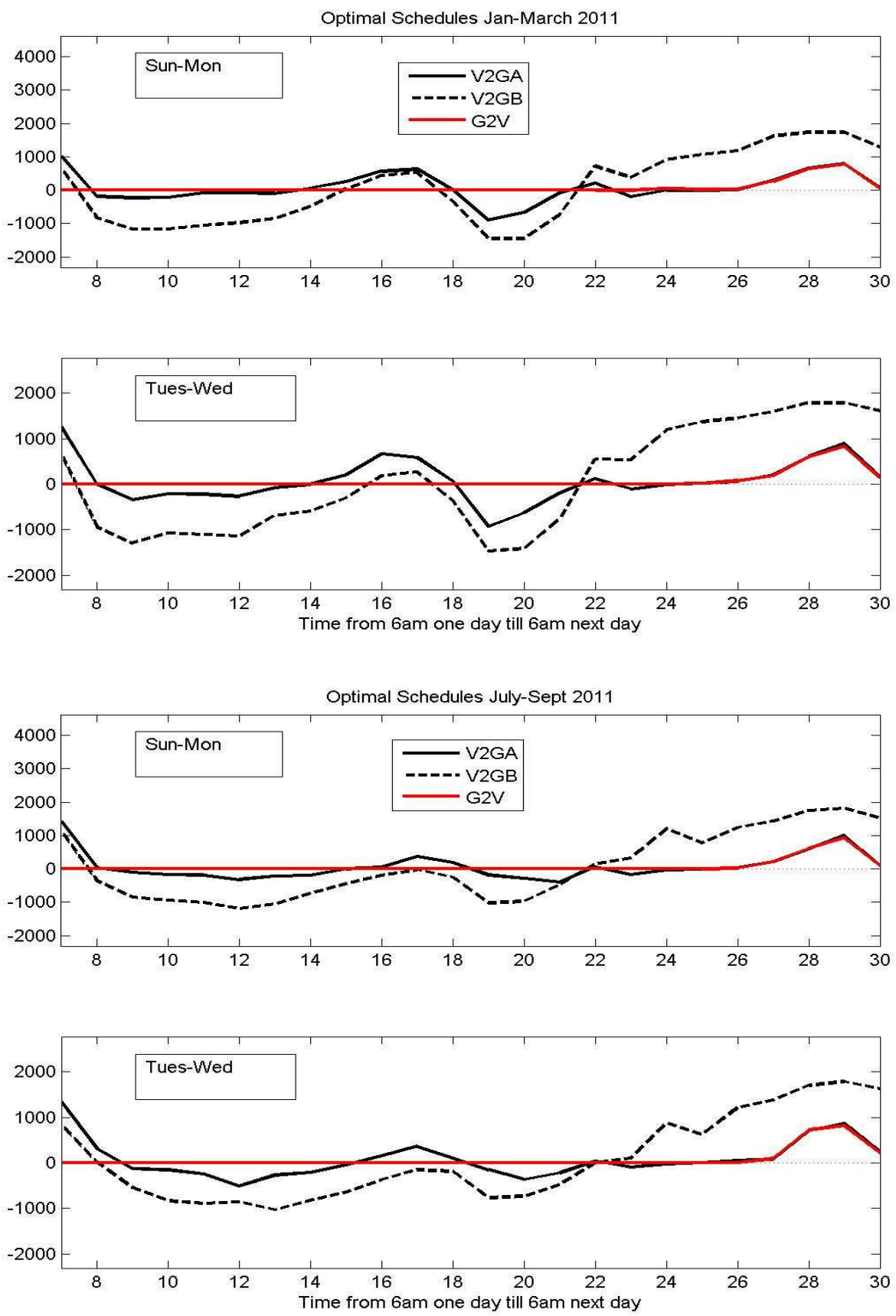

Figure 4: Average of the optimal schedules for the V2G case with scenario $A$ where all EVs arrive at 6am (solid black line), for the V2G case with scenario $B$ where the arrivals of EVs are evenly spread from 6am until 10pm (thick black dotted line) and for the G2V case (solid red line). In each case the averages (in MW) were computed over 13 weeks in 2011, in Jan-March (above) or July-Sept (below). The upper panel in each set of figures corresponds to Sun-Mon; the lower one, to Tues-Wed 

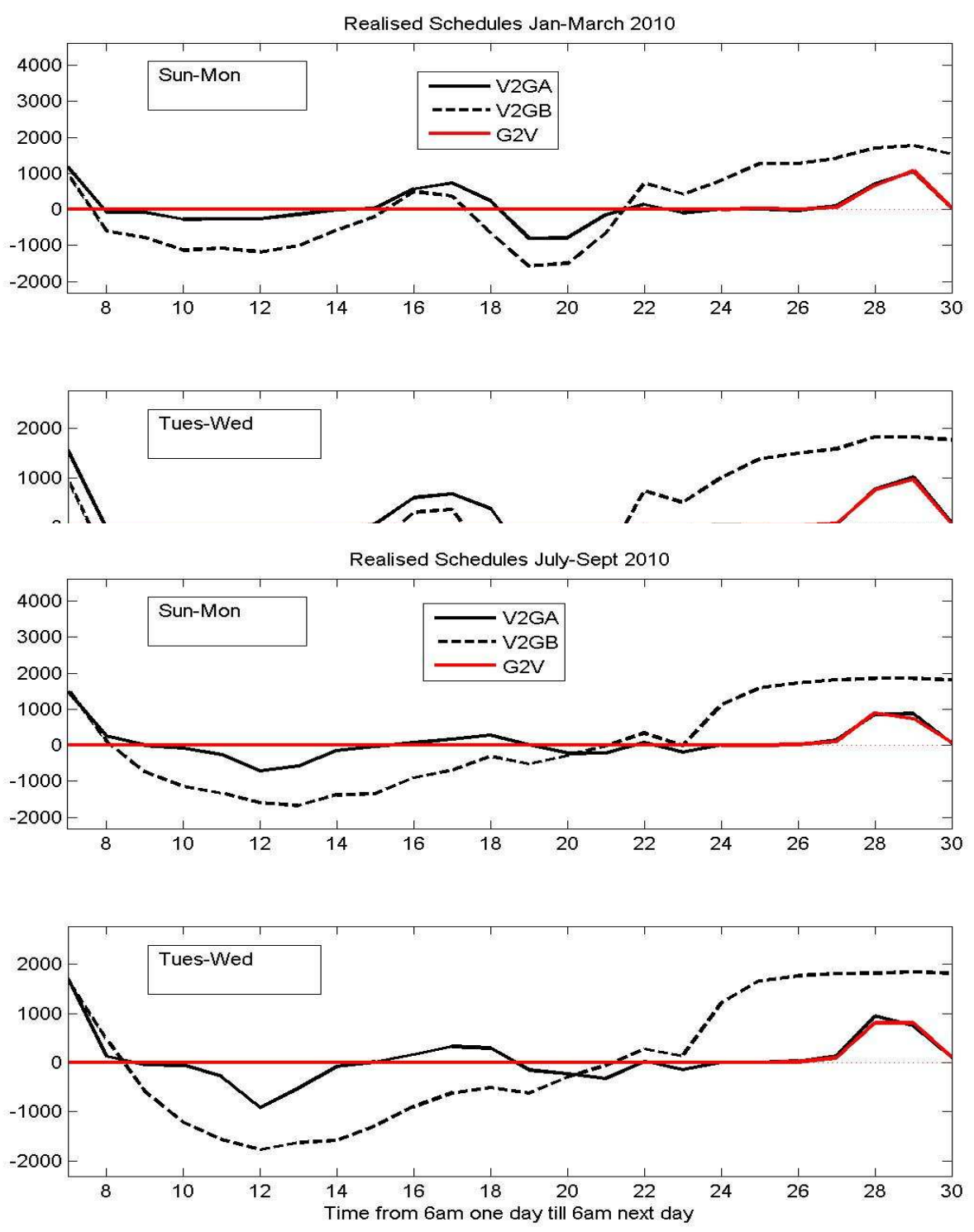

Figure 5: Average of the realised schedules for the V2G case with scenario $A$ where all EVs arrive at 6am (solid black line), for the V2G case with scenario $B$ where the arrivals of EVs are evenly spread from 6am until 10pm (thick black dotted line) and for the G2V case (solid red line). In each case the averages (in MW) were computed over 13 weeks in 2010, in Jan to March (above) or July-Sept (below). The upper panel in each set of figures corresponds to Sun-Mon; the lower one, to Tues-Wed 

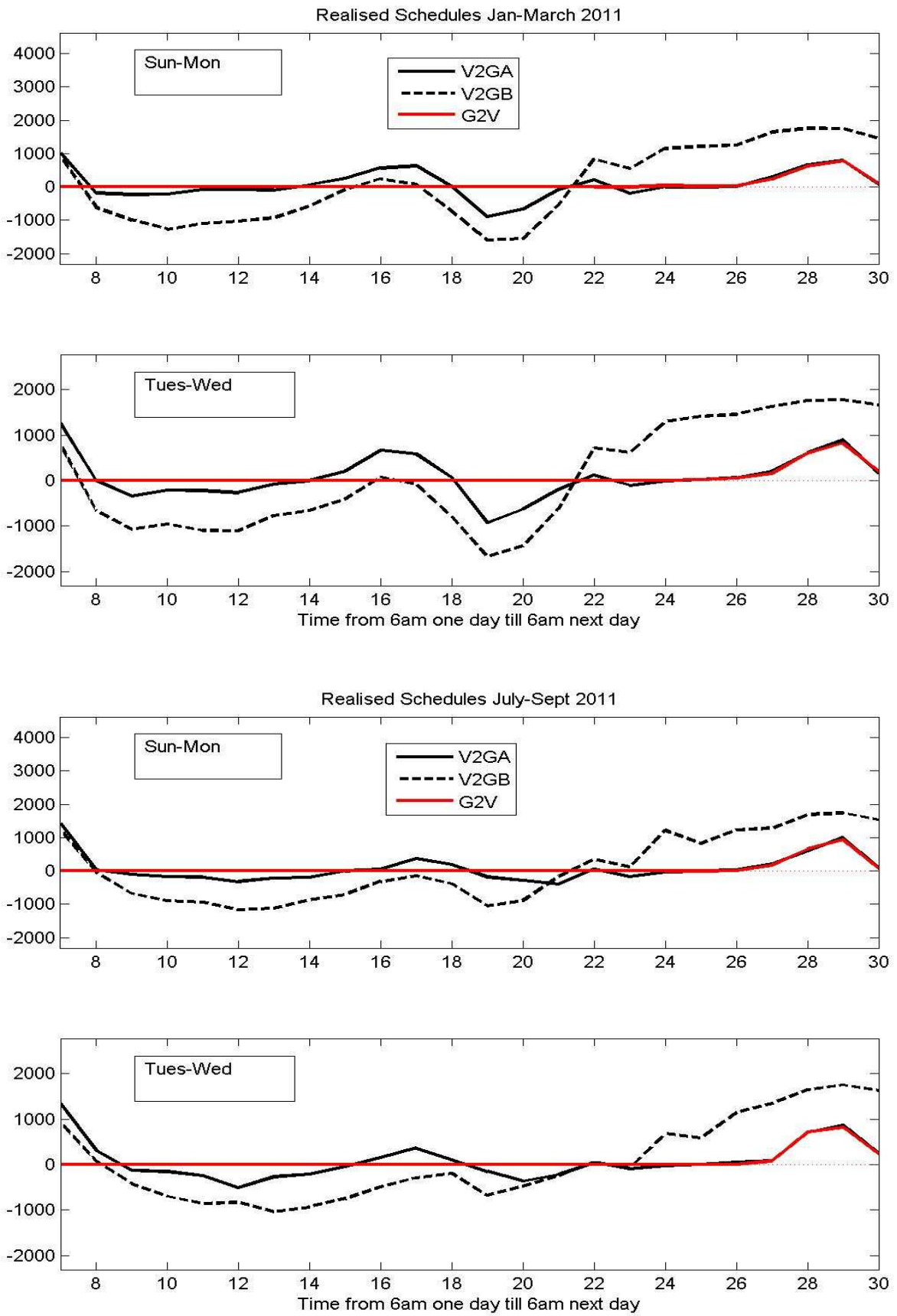

Figure 6: Average of the realised schedules for the V2G case with scenario $A$ where all EVs arrive at 6am (solid black line), for the V2G case with scenario $B$ where the arrivals of EVs are evenly spread from 6am until 10pm (thick black dotted line)and for the G2V case (solid red line). In each case the averages (in MW) were computed over 13 weeks in 2011, in Jan to March (above) or July-Sept (below). The upper panel in each set of figures corresponds to Sun-Mon; the lower one, to Tues-Wed

- $\quad$ For both V2G cases in winter, the BSS sells power during the noon peak period, recharges the batteries during the afternoon when prices are 
lower, then sells power again during the evening peak period and recharges the batteries during the night; in summer, the evening peak price is not as high so less power is sold on the market.

- The recharging schedule for the V2G case scenario A when all the EVs arrive at 6am is quite different from scenario $B$ when the arrivals are spread evenly from 6am until $10 \mathrm{pm}$. Much more power is bought and sold in scenario $\mathrm{B}$.

- The recharging schedule for the G2V is almost the same as for scenario $A$ of the $V 2 G$ case during the night-time (10pm to $6 \mathrm{am}$ ). This is why the solid red line has almost covered up the solid black line.

- The optimal schedules are quite similar to the realised schedules, but both vary from winter to summer because of different usage patterns because electrical heating is widely used in winter in France.

\section{Values generated by carrying out these schedules}

The value generated by implementing these strategies can be either negative (i.e. a cost that the BSS must pay) or positive (i.e. revenue for the BSS). Three sets of values were computed for each case:

- the estimated value obtained by averaging the optimal values for the days in the training set;

- the optimal value (obtained by optimising the schedule ex post)

- the realised value obtained using the proposed schedule and the actual information for the day.

We had expected the estimated value to be a good predictor of the future value but this turned out to be incorrect. To illustrate this point, Figure 7 shows the cross-plot of the estimated value (left) and the realised value (right) as a function of the optimal value for the 24 hour period Sunday to Monday in 2010. The correlation coefficient in the left panel is -0.37 compared 0.97 in the right one. That is, there is a strong correlation between the realised value and the optimal value, but virtually none between the estimated value and the optimal one. Consequently the estimated value will not be considered in the rest of the study. 

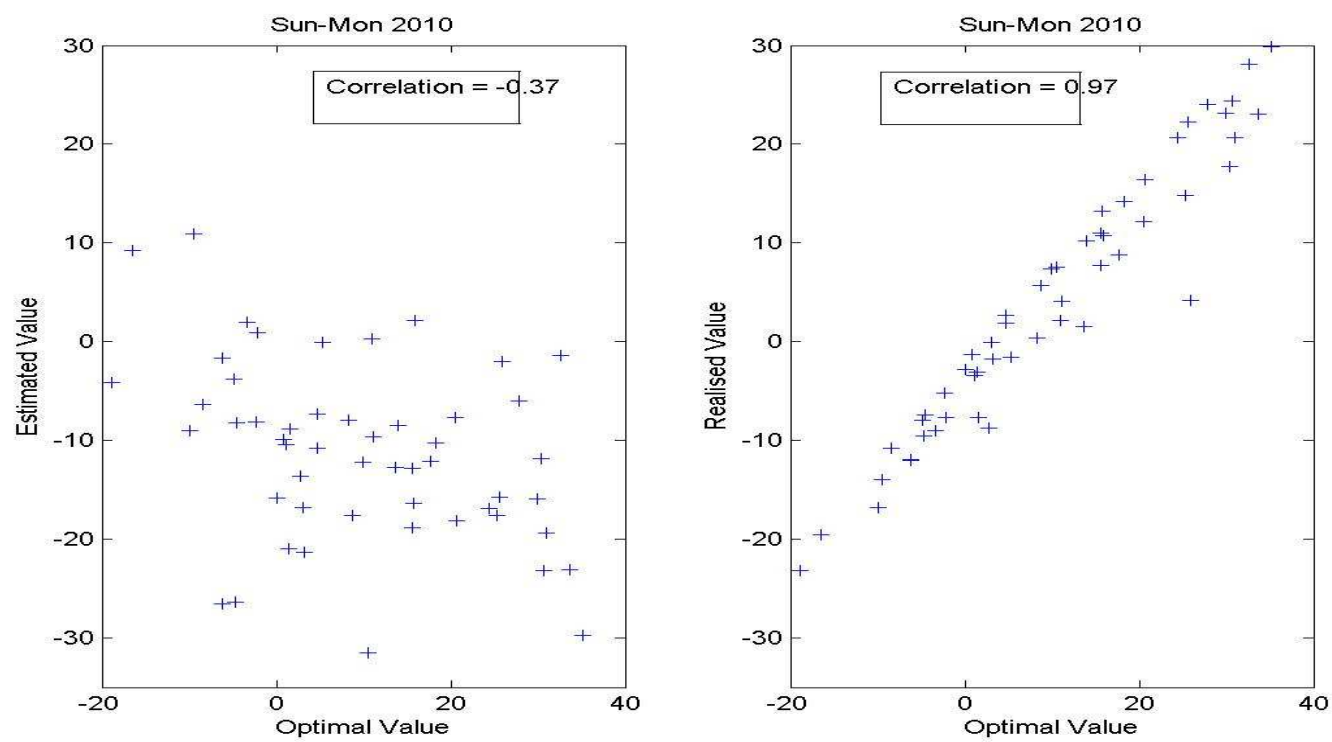

Figure 7: The cross-plots of the estimated value (left) and the realised value (right) as a function of the optimal value for the 24 hour period from Sunday to 6am Monday morning. As the correlation on the left is -0.37 , the estimated value is not a good predictor of optimal value or of the realised value. However the optimal and the realised values are strongly correlated (0.97)

Next we compare the averages of the optimal and the realised values. But before doing this, it is important to note that by definition the optimal value is equal to or greater than the realised value. The only way that the realised value could be equal to the optimal value would be if the recharging schedule obtained from the training set happened to be equal to that by optimising the schedule ex post.

Table 2 gives the averages of the optimal and the realised values for the three cases: V2G scenario A, V2G scenario B and G2V, for 2010 and 2011 if there are no losses when charging and discharging the batteries, while Table 3 gives the corresponding values if there are $5 \%$ losses. As expected, the values for the G2V case are systematically negative (costs). The values for the V2G depend on when the EVs arrive. For scenario $A$, the optimal values are positive on Sunday (revenue) but not for the other days of the week. For scenario $B$, the values are systematically positive (revenue). This highlights the importance of knowing the arrival times of the EVs.

Figures 8 and 9 present the optimal value of the three strategies for each day of the year in 2010 and 2011. The solid black line corresponds to 
Scenario A for the V2G case, the dotted black corresponds to Scenario B of the V2G case while the solid red line is for the G2V case. In each figure the case where there are no losses is in the upper panel, while the lower panels corresponds to the case where there are $5 \%$ losses. The optimal value for G2V case is almost always less than the other two; the optimal value for scenario $B$ of the $V 2 G$ case is almost always higher than the other two.

Table 2: Optimal values (OptVal) and realised values (RVal) for the V2G case scenario $A$ (where all EVS arrive at 6am), for the V2G case scenario $B$ (where the arrivals of the EVs are evenly spread from 6am until 10pm) and for the G2V case, for 2010 and 2011 when there are no losses transferring power to and from the batteries.

\begin{tabular}{|l|l|l|l|l|l|l|l|}
\hline $\mathbf{2 0 1 0}$ & Sun & Mon & Tues & Wed & Thu & Fri & Sat \\
\hline OptValA & 9.83 & -10.90 & -9.60 & -13.36 & -11.87 & -12.19 & -1.54 \\
\hline RValA & 3.95 & -18.04 & -17.58 & -19.85 & -21.92 & -18.20 & -7.71 \\
\hline OptValB & 51.00 & 60.76 & 75.60 & 57.91 & 57.95 & 50.05 & 46.01 \\
\hline RValB & 32.37 & 41.03 & 53.96 & 39.00 & 36.86 & 33.09 & 7.94 \\
\hline OptValG2V & -26.81 & -32.91 & -31.32 & -32.39 & -31.86 & -31.87 & -24.43 \\
\hline RVaIG2V & -27.70 & -33.53 & -32.24 & -33.35 & -32.90 & -32.71 & -25.08 \\
\hline
\end{tabular}

\begin{tabular}{|c|c|c|c|c|c|c|c|}
\hline 2011 & Sun & Mon & Tues & Wed & Thu & Fri & Sat \\
\hline OptValA & 4.71 & -14.70 & -16.92 & -16.16 & -18.63 & -16.89 & -3.41 \\
\hline RValA & -6.06 & -24.91 & -23.71 & -23.03 & -26.40 & -24.32 & -14.27 \\
\hline OptValB & 34.36 & 41.06 & 38.74 & 44.31 & 30.05 & 33.25 & 33.23 \\
\hline RValB & -3.22 & 6.41 & 15.18 & 22.63 & 9.53 & 12.01 & 1.96 \\
\hline OptVaIG2V & -27.60 & -32.83 & -33.66 & -31.38 & -33.76 & -32.77 & -25.56 \\
\hline RVaIG2V & -28.84 & -34.03 & -34.44 & -32.60 & -35.12 & -33.98 & -27.07 \\
\hline
\end{tabular}


We had wondered to what extent the creation of the CWE market would perturb the strategies since the data from before the change was being used afterwards. In particular we had been expecting to see changes in the realised values, or a discontinuity in the optimal value. Looking at Figure 8, there are no obvious differences toward the end of that year. So the strategies are quite stable - even when confronted with a major structural change in the market.

Table 3: Optimal values (OptVal) and realised values (RVal) for the V2G case scenario $A$ (where all EVS arrive at 6am), for the V2G case scenario $B$ (where the arrivals of the EVs are evenly spread from 6am until 10pm) and for the G2V case, for 2010 and 2011 when there is a 5\% losses transferring power to and from the batteries.

\begin{tabular}{|c|c|c|c|c|c|c|c|}
\hline $\mathbf{2 0 1 0}$ & Sun & Mon & Tues & Wed & Thu & Fri & Sat \\
\hline OptValA & 9.72 & -11.07 & -9.73 & -13.41 & -12.09 & -12.33 & -1.74 \\
\hline RValA & 4.00 & -18.27 & -17.89 & -20.30 & -22.23 & -18.42 & -7.88 \\
\hline OptValB & 51.41 & 61.54 & 76.40 & 58.09 & 58.39 & 50.44 & 46.33 \\
\hline RValB & 33.82 & 42.29 & 55.77 & 40.13 & 38.60 & 34.50 & 27.02 \\
\hline OptValG2V & -26.96 & -33.04 & -31.45 & -32.53 & -31.98 & -32.02 & -24.53 \\
\hline RVaIG2V & -27.84 & -33.69 & -32.36 & -33.51 & -32.98 & -32.79 & -25.17 \\
\hline
\end{tabular}

\begin{tabular}{|c|c|c|c|c|c|c|c|}
\hline 2011 & Sun & Mon & Tues & Wed & Thu & Fri & Sat \\
\hline OptValA & 4.58 & -14.97 & -17.15 & -16.33 & -19.02 & -17.11 & -3.66 \\
\hline RValA & -6.30 & -24.96 & -24.13 & -23.48 & -26.54 & -24.95 & -14.55 \\
\hline OptValB & 33.59 & 41.16 & 38.56 & 44.21 & 29.85 & 33.48 & 33.44 \\
\hline RValB & -3.24 & 6.74 & 14.86 & 22.52 & 9.98 & 11.64 & 1.97 \\
\hline OptVaIG2V & -27.78 & -33.03 & -33.83 & -31.54 & -33.97 & -32.92 & -25.72 \\
\hline RVaIG2V & -29.06 & -34.28 & -34.61 & -32.81 & -35.29 & -34.10 & -27.20 \\
\hline
\end{tabular}



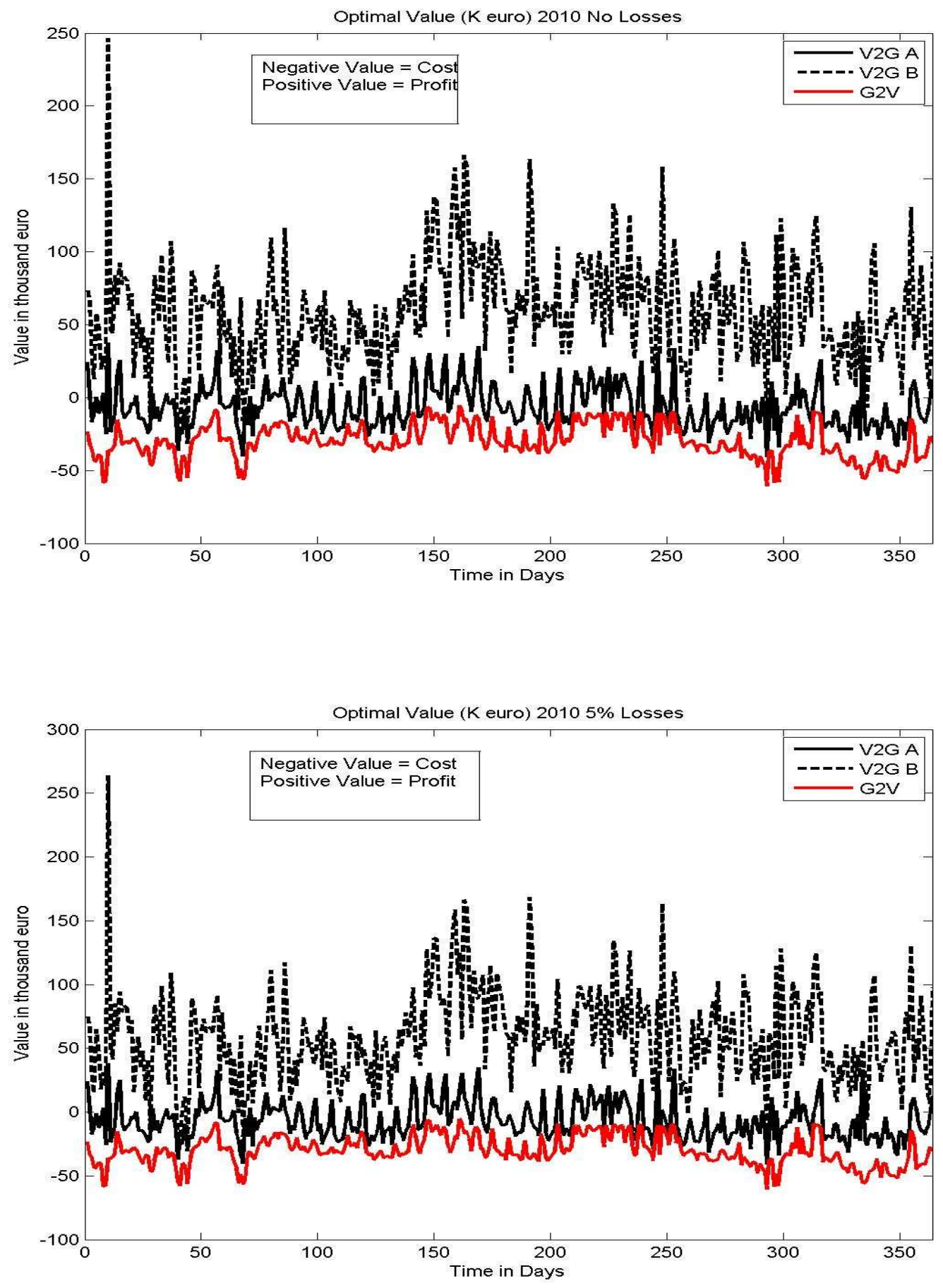

Figure 8: The optimal values are presented for scenario A of the V2G case (solid black line), for scenario $B$ of the V2G case (thick black dotted line) and the G2V case (solid red line), for the cases where there are no losses (upper panel) and when there are 5\% losses, for 2010. The optimal value for G2V case is almost always less than the other two; the optimal value for scenario B of the V2G case is almost always higher than the other two. 

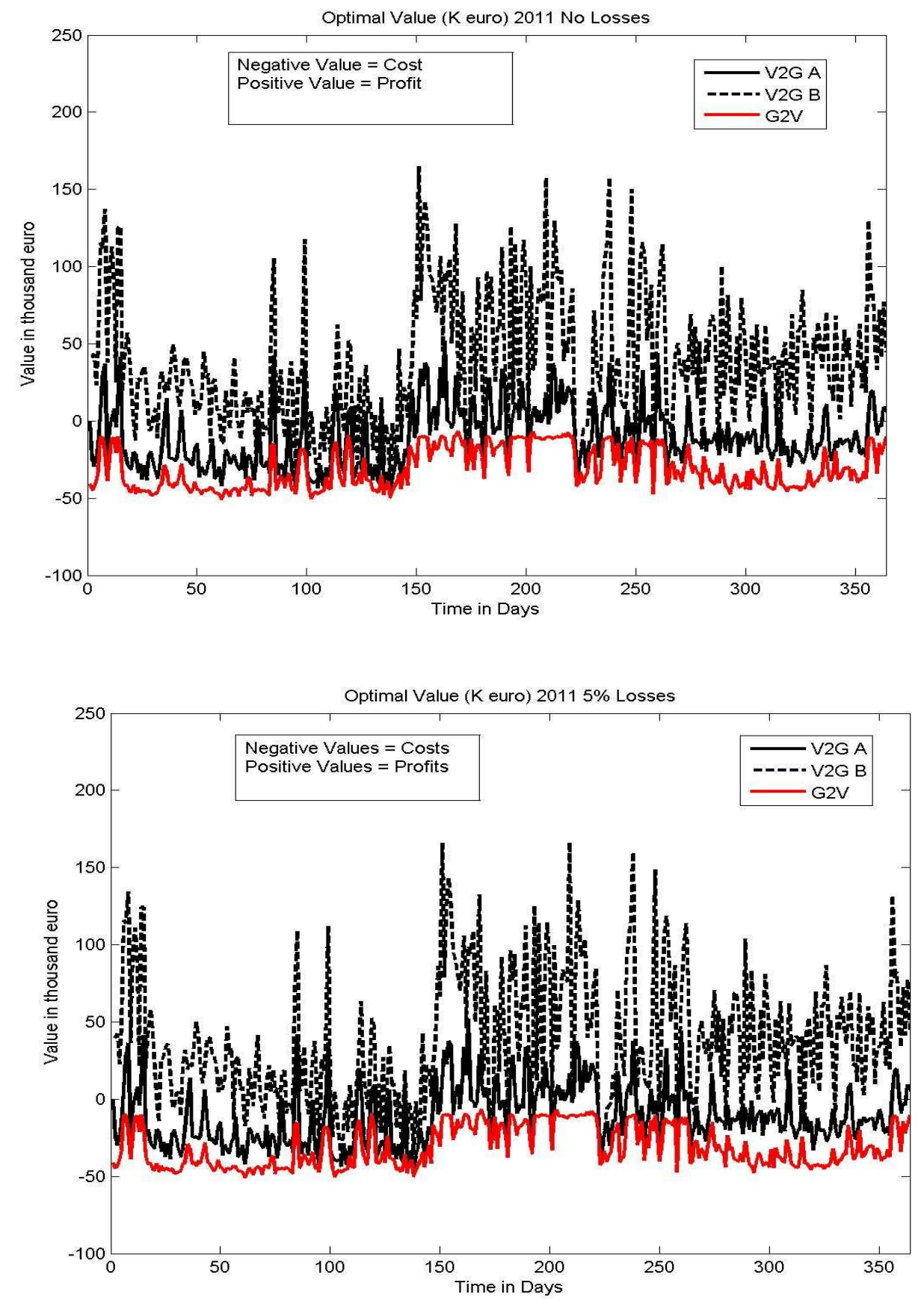

Figure 9 The optimal values are presented for scenario $A$ of the V2G case (solid black line), for scenario $B$ of the V2G case (thick black dotted line) and the G2V case (solid red line), for the cases where there are no losses (upper panel) and when there are 5\% losses, for 2011. The optimal value for G2V case is almost always less than the other two; the optimal value for scenario B of the V2G case is almost always higher than the other two. 
Impact of the strategies for recharging the batteries on the day-ahead market

As the strategies were designed to optimise the revenue for the BSS, we want to find out what effect this will have on the wholesale electricity market. To be more precise, we are interested in their impact on the hourly dayahead prices for electricity and on the volumes of transactions.

The average prices were computed over a 13 week period in winter and again in summer, in 2010 and 2011. Figures 10 and 11 show these for winter and summer 2010, and winter and summer 2011, respectively. As before the averages are shown for the 24 hour period from 6am Sunday until 6 am Monday, and from 6 am Tuesday until 6 am Wednesday. Four curves are shown in each figure: a solid black line for scenario A for the V2G case, a thick black dotted line for scenario B for the V2G case, a solid red line for the G2V case and finally a fine black line showing the original prices (that is, the observed prices). The red line corresponding to the G2V case is only shown from $10 \mathrm{pm}$ until $6 \mathrm{am}$ because it does not affect prices or volumes during the daytime.

As expected the original prices are higher than those for the two V2G cases during the evening peak hour especially in winter. Scenario $B$ in the V2G case leads to a greater drop at peak hours and to a correspondingly higher price in the early morning off-peak period. In contrast to electricity prices which drop during peak hours in the V2G cases, the volumes of electricity bought and sold through the auction market rise in both peak hours and off peak periods. This is particularly marked for scenario $B$ in the V2G case. In the case studied where $300,000 \mathrm{EVs}$ have signed up with the BSS, the impact on the market prices and volumes are not very marked. But the French government has plans to have 10 times as many EVs on the roads. In that case the impact of coordinated changing would lead to a much more pronounced drop in peak prices. 
Average Prices dan-March 2010
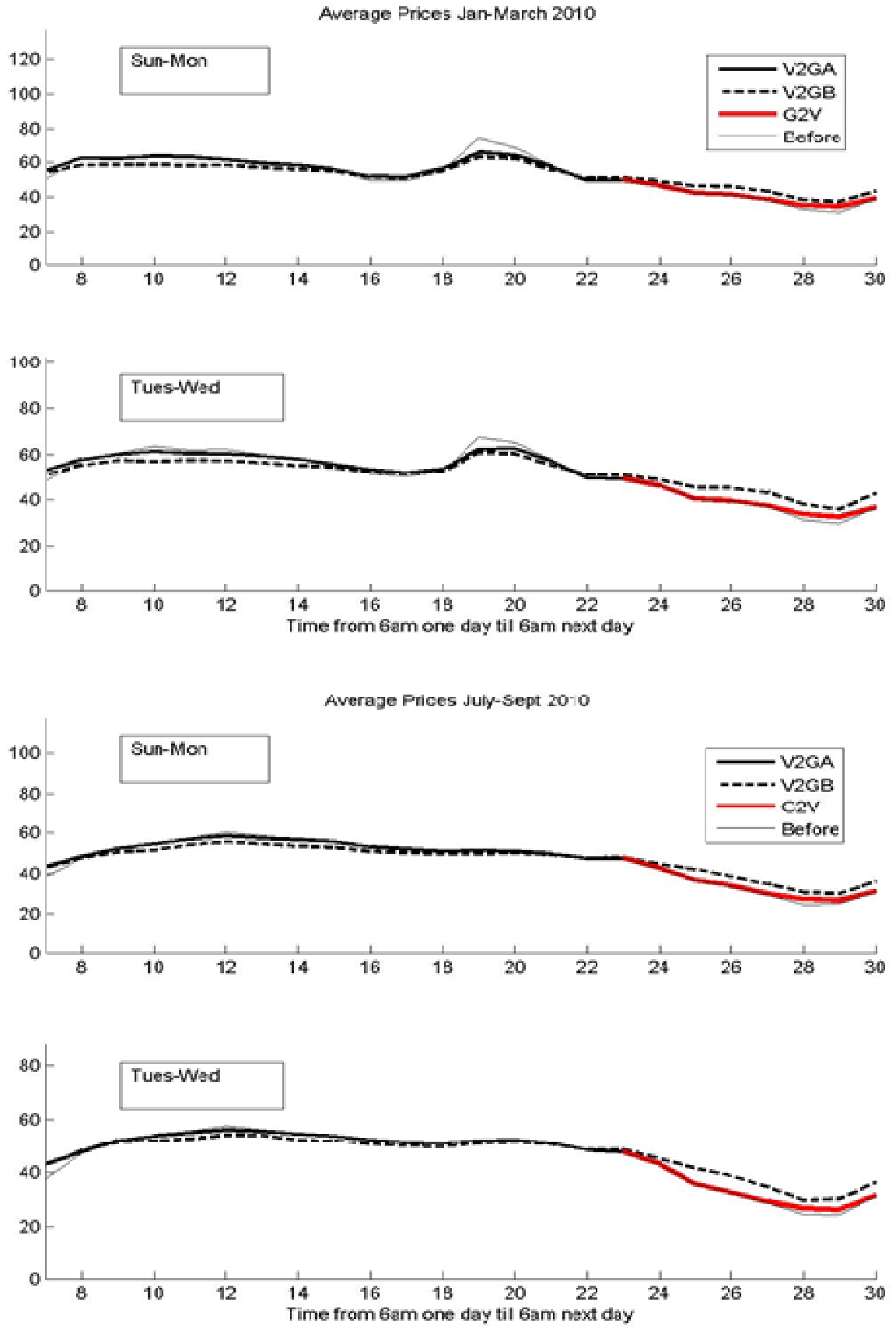

Figure 10: Average price on the day-ahead market in France: for scenario $A$ of the V2G case (solid black line), for scenario $B$ of the V2G case (thick black dotted line), for the G2V case (solid red line) and the original prices (thin black line), for a typical weekday and for the weekend, for winter 2010 (upper panel) and summer 2010 (lower panel) 

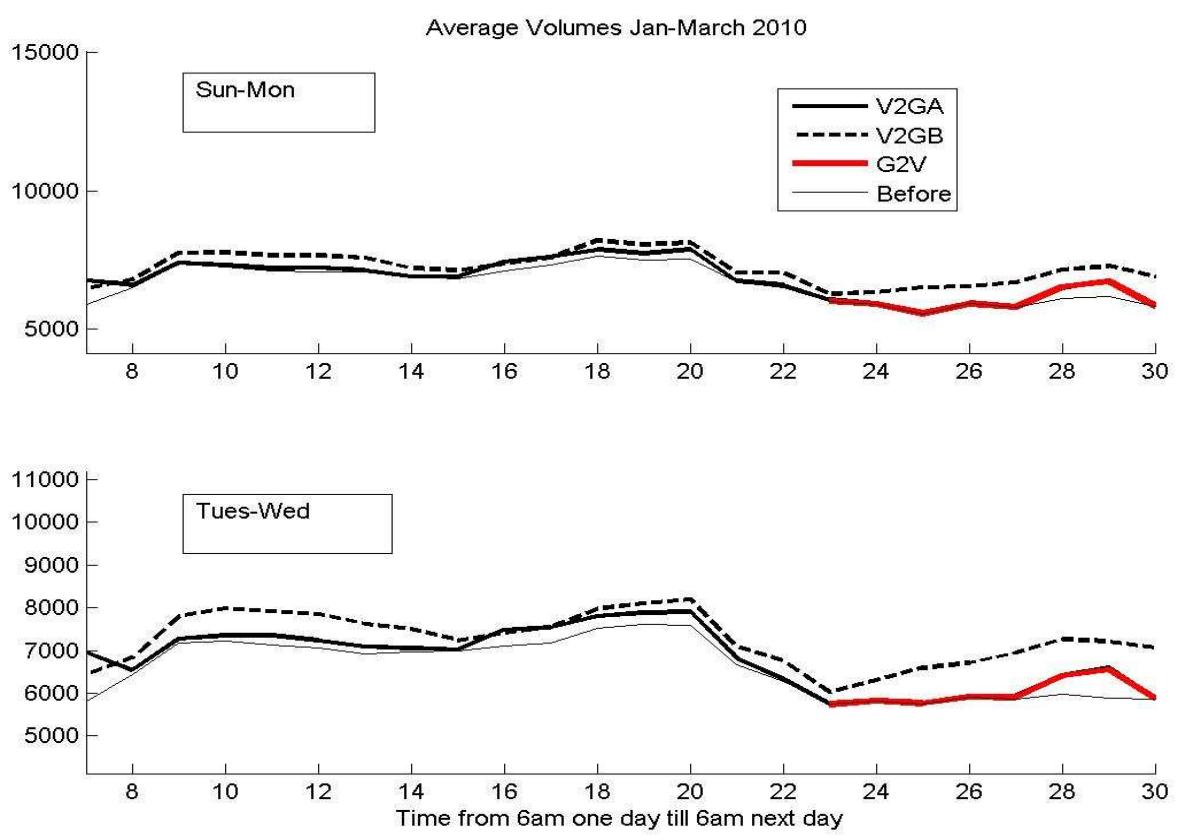

Average Volumes July-Sept 2010
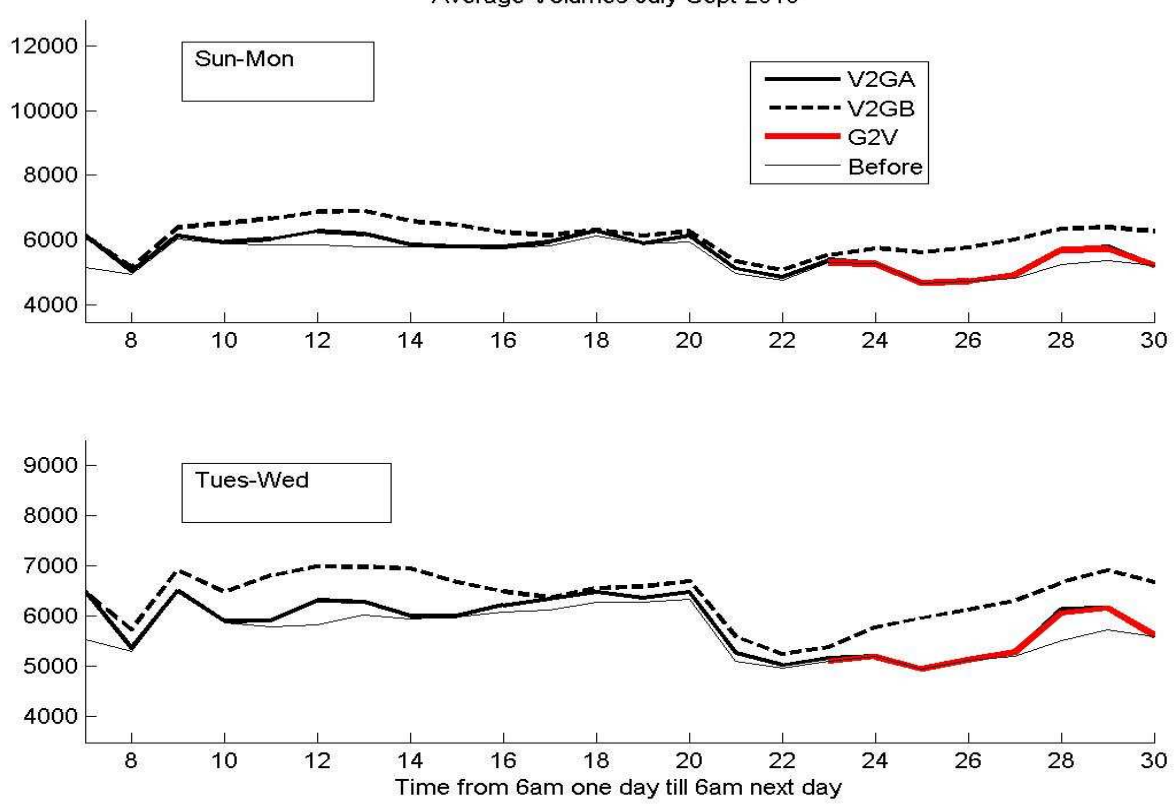

Figure 11: Average volumes on the day-ahead market in France: for scenario $A$ of the V2G case (solid black line), for scenario $B$ of the V2G case (thick black dotted line), for the G2V case (solid red line) and the original prices (thin black line), for a typical weekday and for the weekend, for winter 2010 (upper panel) and summer 2010 (lower panel) 


\section{Discussion and Conclusions}

Most papers that study the recharging of electric vehicles focus on charging the batteries at home and in the work-place. The alternative is for owners to exchange the battery at a specially equipped battery switch station (BSS). This paper proposes strategies for the BSS to buy and sell the electricity through the day-ahead auction market. To do this the BSS would have to submit firm offers specifying the amounts of electricity that it is offering to buy or sell during each hour of the day, before noon on the day prior to delivery. So the management needs a procedure for determining those quantities.

We determined what the optimal strategies would have been for a large fleet of EVs each day in 2010 and 2011, for the V2G and the G2V cases. As one of the key factors influencing the optimal strategies for the V2G case is the expected arrival time of the EVs, two fairly extreme possibilities were considered: firstly an unfavourable case where all the EVs arrive first thing in the morning and secondly when their arrivals are spread evenly throughout the day. Another factor that was taken into account was losses when charging and discharging batteries. Table 4 gives the annual revenue in millions of euros from buying and selling on the day-ahead market, for the three scenarios considered with and without losses. Positive values correspond to revenue while negative ones are costs. These can be compared with the amount ( $27 \mathrm{M}$ euro) that it would cost to buy the same quantity of electricity at the benchmark base-load price of $40 €$ per MWh at which the government obliges EDF to sell nuclear power to competitors. 
Table 4: Annual revenue in millions of euro for the three scenarios considered, with and without losses, for 2010 and 2011. Positive values correspond to revenue; negative ones, to costs incurred. These should be compared to the benchmark cost (-27 M€) at the benchmark base-load price of 40 euro per MWh.

\begin{tabular}{|l|c|c|l|c|c|}
\hline \multicolumn{7}{|c|}{ Optimum Value } \\
\hline 2010 & No losses & \%5 Losses & 2011 & No losses & \%5 Losses \\
\hline V2G A & $-4.99 \mathrm{M} €$ & $-5.10 \mathrm{M} €$ & V2G A & $-8.24 \mathrm{M} €$ & $-8.41 \mathrm{M} €$ \\
\hline V2G B & $40.49 \mathrm{M} €$ & $40.15 \mathrm{M} €$ & V2G B & $25.67 \mathrm{M} €$ & $25.64 \mathrm{M}$ \\
\hline G2V & $-21.28 \mathrm{M} €$ & $-21.37 \mathrm{M} €$ & G2V & $-21.88 \mathrm{M} €$ & $-22.00 \mathrm{M} €$ \\
\hline \multicolumn{7}{|c|}{ Realised Value } \\
\hline 2010 & No losses & \%5 Losses & 2011 & No losses & \%5 Losses \\
\hline V2G A & $-9.99 \mathrm{M} €$ & $-10.16 \mathrm{M} €$ & V2G A & $-14.35 \mathrm{M} €$ & $-14.57 \mathrm{M} €$ \\
\hline V2G B & $27.37 \mathrm{M} €$ & $26.39 \mathrm{M} €$ & V2G B & $6.48 \mathrm{M} €$ & $6.48 \mathrm{M} €$ \\
\hline G2V & $-21.87 \mathrm{M} €$ & $-21.96 \mathrm{M} €$ & G2V & $-22.74 \mathrm{M} €$ & $-22.86 \mathrm{M} €$ \\
\hline
\end{tabular}

Looking at the figures we see firstly that all of the strategies are more cost-effective than buying directly from a utility. Secondly, there is little difference between the cost of charging the batteries in 2010 and 2011 for the G2V case, but the differences are quite marked for both the V2G cases. There is a significant difference between the revenue that can be generated in the V2G case for scenario $B$ and the cost for scenario A. This highlights the importance of having a good understanding of arrival times of the EVs. It also suggests that it might be worthwhile proposing advantageous tariffs for EV owners who exchange their batteries at certain times in the day.

As the optimal strategies were found for a reasonably large fleet of $300,000 \mathrm{EVs}$, the quantities of electricity bought and sold will displace the market equilibrium. Table 5 gives the new average prices for the 8 hour period from 10pm to 6am (when batteries are charged in the G2V case) and for the rest of the day, and also the average price for the same times in the original data. As expected, the night price rose in all three scenarios and the V2G prices decreased in the day-time. Much more marked effects could be expected with a larger fleet. 
Table 5: Average prices for electricity, for the three scenarios considered, with and without losses, during the times from 6am to 10pm and from 10pm to 6am for 2010 and 2011.

\begin{tabular}{|l|c|c|l|l|l|}
\hline & \multicolumn{2}{|c|}{ H7 to H22 } & & \multicolumn{2}{c|}{ H23 to H6 } \\
\hline 2010 & No losses & \%5 Losses & 2010 & No losses & \%5 Losses \\
\hline V2G A & 52.57 & 52.63 & V2G A & 37.86 & 37.90 \\
\hline V2G B & 50.98 & 51.10 & V2G B & 41.00 & 41.19 \\
\hline G2V & NA & NA & G2V & 37.94 & 37.98 \\
\hline Original & 52.76 & NA & Original & 37.26 & NA \\
\hline 2011 & No losses & \%5 Losses & 2011 & No losses & \%5 Losses \\
\hline V2G A & 54.27 & 54.34 & V2G A & 39.12 & 39.19 \\
\hline V2G B & 52.23 & 52.40 & V2G B & 42.84 & 43.09 \\
\hline G2V & NA & NA & G2V & 39.31 & 39.38 \\
\hline Original & 54.28 & NA & Original & 38.24 & NA \\
\hline
\end{tabular}

One important feature of the results is the stability of the strategies during the last two months of 2010 just after the creation of the CWE market. As data from the French market were used to set up the strategy after the French and German markets were combined, we had wondered how robust the strategies would be. No instabilities were found. We think that this is because the basic patterns for electricity consumption remained the same despite the structural changes in the market.

Finally, the implications of this study for policy-making should be drawn. As we analysed the results of this study, it occurred to us that BSS might be an economically viable alternative to charging the batteries at home or at the workplace, and not just a back-up for longer journeys. The advantages of BSS are:

1. Rather than having to upgrade the whole electricity distribution network and install millions of smart meters, the grid would only have to be upgraded for several thousand BSS, granted at a higher voltage;

2. The owners of EVs do not need to have the same level of trust in the aggregator since they just drop off the depleted battery and get a 
fully charged battery in exchange. No one is charging/discharging the battery in THEIR car. The batteries remain anonymous;

3. From a mathematical point of view it is much simpler to optimize the charging/discharging of a large set of anonymous batteries. There is no need to know the owners' travel details individually, or to store and process vast quantities of private information;

4. Most interesting of all, no new special incentives are needed to convince the BSS operator to charge the batteries in a socially optimal way during offpeak periods. It is in his/her interest to reduce the cost of charging the EVs to increase the profitability of the business, and as we have shown, in V2G mode this achieves the socially desirable outcome of having the BSS sell power to the grid during peak hours (thereby reducing prices and the need for new peaking power plants) and buying during off-peak periods when some of the generation capacity is under-used.

This is why we think that if the cost of the batteries drops sufficiently and if they resist the additional wear-and-tear due to the additional charging/ discharging cycles, a pure BSS business might actually be a viable economic proposition - as well as being socially useful.

\section{References}

Badey, Q. (2012) Etude des mécanismes et modélisation du vieillissement des batteries lithium-ion dans le cadre d'un usage automobile, PhD Thesis, Université Paris-Sud, 260pp available from http://tel.archivesouvertes.fr/docs/00/69/33/44/PDF/VA2 BADEY QUENTIN 22032012.pdf

Camus C., T. Farias, and J. Esteves 2011 Potential impacts assessment of plug-in electric vehicles on the Portuguese energy market, Energy Policy, 39 (10) Oct 2011 pp5883-5897

Dang V.T.T., C. Fournier, S. Morel, J. Adnot \& J. Oostebaan (2010) Batteries Management for Minimization of Electric Vehicles' Environmental Impacts in A Life Cycle Assessment Framework, EcoBalance2010, $9^{\text {th }}$ International Conference on EcoBalance, 9-12 Nov, 2010, Tokyo 
Denholm, P., and W. Short, 2006 An Evaluation of Utility System Impacts and Benefits of Optimally Dispatched Plug-In Hybrid Electric Vehicles. Technical Report NREL/TP-620-40293. National Renewable Energy Laboratory, Golden, CO.

Finn, P., C. Fitzpatrick and D. Connolly, (2012) Demand side management of electric car charging: Benefits for consumer and grid, Energy (42 (2012) 358363

Hacker, F., R. Harthan, F. Matthes \& W. Zimmer, (2009), Environmental impacts and impact on the electricity market of a large scale introduction of electric cars in Europe - Critical Review of Literature, ETC/ACC Technical Paper $2009 / 4$

Hadley S.W. and A. Tsvetkova (2008) Potential impacts of plug-in electric vehicles on regional power generation, $71 \mathrm{pp}$, available from http://www.ornl.gov/info/ornlreview/v41 1 08/regional phev analysis.pdf

Han, SE, SO Han and K. Sezaki (2010) Development of an optimal vehicle-to-grid aggregator for frequency regulation, IEEE Transaction on Smart Grid, 1:6572, June, 2010

Kempton W. and J. Tomic, (2005) Vehicle-to-grid power fundamentals: calculating capacity and net revenue, J. Power Sources 144(1) 280-294

Lyon, T., M. Michelin, A. Jongejan and T. Leahy, (2012) Is "smart-charging" policy for electric vehicles worthwhile?, Energy Policy 41 (2012) 259-268

Ma Z., D. Callaway and I. Hiskens (2010) Decentralized charging control for large populations of plug-in electric vehicles: Application of the Nash certainty equivalence principle. IEEE International Conference on Control Applications, pp191-195, Sept 2010

Neuhoff, K., R. Boyd, T. Grau, B. Hobbs, D. Newbery, F. Borggrefe, J. Barquin, F. Echavarren, J. Bialek, C. Dent, C. von Hirschhausen, F. Kunz, H. Weight, C. Nabe, G. Papaefthymiou, and C. Weber, (2011) Reshaping: Shaping an effective and efficient European renewable energy market, D20 Report: Consistency with other EU policies, System and Market Integration- A Smart Power Market at the Centre of a Smart Grid, 110pp

Rousselle, M. (2009) Impact of the Electric Vehicle on the electric system, MSc Thesis KTH 
RTE (2009) Generation Adequacy Report on the electricity supply-demand balance in France, 172pp available from www.rte-france.fr

Schneider, S.J., R. Bearman, H. McDermott, X. Xu, S. Benner \& K. Huber (2011) An assessment of the price impact of electric vehicles on PJM market: $A$ joint study by PJM \& Better Place, 30pp available from http://www.betterplace.com/uploads/ckfinder/files/Press\%20Kits/An Assess ment of the Price Impacts of Electric Vehicles on the PJM Market.pdf? awesm=btrp.Ic fXd\&utm campaign=\&utm medium=btrp.lccopypaste\&utm source=direct-btrp.Ic\&utm content=awesm-publisher

Scott M.J., M. Kintner-Meyer, D.B. Elliott and W.M. Warwick (2007) Impacts assessment of plug-in hybrid vehicles on electric utilities and regional U.S. power grids: Part 2: Economic assessment, 18pp available from http://www.roguevalleycleancities.org/images/news.html/PNNL\%20Articles/P HEV Economic Analysis Part2 Final.pdf

Sivorski, T. (2011) Nodal pricing project in Poland, presented at the $34^{\text {th }}$ IAEE International Conference, Stockholm, 21 June 2011

Taheri, N., R. Entriken and Y. Ye, (2011) A dynamic algorithm for facilitated charging of plug-in electric vehicles, $16 \mathrm{pp}$

Tomic, J., and W. Kempton, (2007) Using fleets of electric-drive vehicles for grid support, J. Power Sources 168(2) 459-468

Tomé Saraiva, J., (2007) Iberian Electricity market: Difficulties, advantages and challenges, 37pp, available from http://www.cefes.untz.ba/pdf/3 CEFES Tuzla JTS Final.pdf

Wu, D., D.C. Aliprantis and L. Ying (2011) Load scheduling and dispatch for aggregators of plug-in electric vehicles. IEEE Transactions on Smart Grid, Special Issue on Transportation Electricification and Vehicle-to-Grid Applications, May 2011 